\title{
ERGONOMÍA EN LOS SISTEMAS DE SALUD: EL ERGÓNOMO COMO PACIENTE Y ACUDIENTE
}

\author{
ERGONOMICS IN HEALTHCARE SYSTEMS: THE ERGONOMIST AS A PATIENT AND AS \\ A CAREGIVER
}

\author{
Gabriel García-Acosta* \\ Karen Lange-Morales ${ }^{* *}$
}

\begin{abstract}
Resumen: La seguridad del paciente, el uso de dispositivos médicos, procesos que se llevan a cabo en las instituciones de salud, así como los sistemas de salud en sí, son tópicos que han sido abordados en mayor o menor medida por la ergonomía, siendo en su gran mayoría estudios realizados por ergónomos en donde actúan como observadores de la condición, sin haber necesariamente vivido dicha situación. Este artículo muestra otra faceta de estos eventos, partiendo de las vivencias de dos ergónomos que, estando en las situaciones de paciente o acudiente, reflexionan sobre lo vivido en varios procesos de enfermedad que debieron enfrentar y superar. El material de análisis son las anécdotas registradas por los ergónomos, como método fenomenológico - hermenéutico, de donde surgen reflexiones sobre las implicaciones de los procesos de atención de la enfermedad para la restitución de la salud de las personas, desde un enfoque ético. El reconocimiento de las anécdotas como instrumentos de investigación en la ergonomía, superan el abordaje hegemónico de esa disciplina, esbozando la utilidad que esta aproximación puede tener para contribuir a la identificación de categorías relevantes para el mejoramiento de los sistemas de salud desde una visión holística.
\end{abstract}

Palabras clave: Ergonomía, ética, anécdotas, fenomenológico-hermenéutico, paciente, sistema de salud.

\begin{abstract}
Patient safety, the use of medical devices, processes that are carried out in health institutions, as well as the health systems themselves, are topics that have been addressed to a greater or lesser extent by ergonomics, being in their the vast majority of studies carried out by ergonomists in which they act as observers of the condition, without necessarily having experienced this situation. This article shows another facet of these events, starting from the experiences of two ergonomists who, being in the situations of patient or caregiver, reflect on what they have experienced in various disease processes that they had to face and overcome. The analysis material are the anecdotes recorded by the ergonomists, as a phenomenological - hermeneutical method, from which reflections arise on the implications of the disease care processes for the restitution of people's health, from an ethical approach. The recognition of anecdotes as research instruments in ergonomics, these elements go beyond the hegemonic approach of that discipline, outlining the usefulness that this approach may have to contribute to identifying relevant categories for the improvement of health systems from a holistic perspective.
\end{abstract}

"Universidad Nacional de Colombia. Bogotá, Colombia. Correo electrónico: ggarciaa@unal.edu.co. Orcid: https://orcid.org/oooo-0003-2073-9745. Autor de correspondencia.

**Universidad Nacional de Colombia. Bogotá, Colombia. Correo electrónico: klangem@unal.edu.co. Orcid: https://orcid.org/o0oo-0003-0775-0800 
Keywords: Ergonomics, ethics, anecdotes, phenomenological-hermeneutical, patient, health system.

Recepción: 18.05.2021 / Revisión: 14.06.2021 / Aceptación: 03.08.2021

\section{Introducción}

Los sistemas de salud, entendidos como el complejo de instituciones, normativas y personas que atienden el proceso salud - enfermedad de una población determinada, tienen grandes variaciones, no solo de país a país, sino entre los mismos ciudadanos. Hay países que incluyen la protección de la gente en el futuro mediante sistemas pensionales y establecen un subsistema específico para la salud laboral, mientras que otros solo establecen diferenciaciones entre lo público y lo privado. Así, dependiendo de dónde se viva y de los recursos con que se cuente, la experiencia de atención varía significativamente.

Los autores hemos tenido la oportunidad de vivir tanto en América Latina como en Europa Central, en concreto, Guatemala, México, Colombia y Alemania. En estos países hemos recurrido a los sistemas de salud, lo que nos ha permitido no solo vivenciar sus diferencias por las condiciones inherentes a las condiciones mismas de cada sistema, sino han sido una oportunidad para reflexionar sobre lo que acontece en tales experiencias, desde una perspectiva diferenciada: la ergonomía. Finalmente, quienes nos dedicamos a la ergonomía somos especialistas en "ver trabajar”, ¿’por qué no entonces reflexionar sobre tales sistemas desde la experiencia vivida, a la luz de los conocimientos en ergonomía?

Partiendo de la experiencia de más 30 años dedicada al estudio o aplicación de la ergonomía, este artículo atiende el llamado de la convocatoria del presente número con un objetivo particular: a partir de la reflexión sobre las experiencias vividas en el sistema de salud, materializadas en forma de narrativas anecdóticas, dar luces que contribuyan a transformar los sistemas de salud desde la disciplina de la ergonomía. Ahora bien, para pasar de la anécdota a las contribuciones, es necesario dar un paso intermedio de análisis i.e. relacionar las narrativas con categorías comúnmente empleadas en la ergonomía.

En línea con lo anterior, este artículo responde dos preguntas. La primera interrogante relaciona el contexto histórico, el sistema ergonómico y el sistema de salud en cada una de las anécdotas incluidas i.e. ¿cómo se pueden relacionar el contexto histórico, el sistema ergonómico y el sistema de salud, a partir de la reflexión de las anécdotas? La segunda pregunta, la cual le da sentido a este documento, busca responder la utilidad del análisis de estas anécdotas desde un enfoque ético i.e. ¿̇cómo puede la ergonomía, a partir del análisis de estas anécdotas, contribuir a transformar los sistemas de salud?

\section{Materiales y métodos}

El abordaje de este trabajo se inscribe en la investigación cualitativa-interpretativa, como método fenomenológico-hermenéutico (Fuster, 2019). También está alineado con los 
postulados de Banchs (2007) quien reconoce el debate de la objetivación entre la ciencia y el sentido común. La construcción o escritura de anécdotas puede tener varios enfoques: uno hacia la construcción de situaciones hipotéticas pero basadas en eventos reales, para discernir dilemas éticos, por ejemplo (Wilks, 2004); otro, que incluye la narración de eventos reales, sucedidos a quien lo cuenta, con el fin de compartir, enseñar o reflexionar sobre lo acontecido (Turabián-Fernández \& Pérez-Franco, 2015). Este es el enfoque utilizado en las narrativas desplegadas en el presente artículo.

En la revisión de literatura en castellano, que estableciera la relación entre ergonomía y descripción anecdótica, lo más cercano es el trabajo de Sebastián-Cárdenas (2014). Él argumenta la necesidad de establecer un marco teórico para permitir al ergónomo implementar una metodología a partir de la narrativa, de manera que se pueda analizar o interpretar lo que él denomina como "espacios semióticos", convirtiéndola en una metodología de la actividad con énfasis psico-sociológico, que despliega nuevas maneras de comprender y transformar las interacciones entre las personas y los sistemas. Dentro de las posibles opciones de uso de la narración como instrumento de análisis o como objeto de estudio en sí, nosotros optamos por enmarcar la anécdota como parte de una forma de narración y como instrumento para la ergonomía. En general, la narración tiene un sentido discursivo, con un relato concreto y personal, que devela una historia que se conforma por una cadena de eventos, en donde para el caso de la anécdota, el personaje principal es el que reconstruye las historias de vida (textualizadas), a partir de los eventos significativos que lo marcaron y que se constituyen en los más significativos.

Para Sebastián-Cárdenas (2014), la narración se puede ver desde diferentes planos de análisis, esto es: ontológico, epistemológico, metodológico, técnico y ético. Nosotros lo abordamos desde lo ético, buscando analizar desde la permanente reflexión y respuesta a la pregunta ¿cómo puede contribuir el análisis de estas anécdotas, desde la ergonomía, a transformar el sistema de salud? Como desarrollo metodológico nos interesa encontrar en las anécdotas, los impulsos significativos semióticos (denotaciones y connotaciones), junto con la ubicación histórica y geográfica, que otorga un contexto sociocultural situado de los sistemas de salud y que permiten establecer, a manera de aproximación, una serie de sugerencias, cursos de acción, cambios coyunturales o estructurales a los sistemas de salud.

Las experiencias de hospitalización ocurrieron solo en América Latina, pero las experiencias de atención ambulatoria sucedieron en los dos continentes. Dado que la criticidad varía significativamente entre las vivencias en una hospitalización versus la atención ambulatoria, el análisis lo dividimos en estas dos condiciones. Las anécdotas que se incluyen sucedieron entre 1995 y 2020. El criterio de selección fue el impacto que tuvieron en nuestras vidas y que, por lo mismo, nos llevaron a recordarlas e inclusive compartirlas con otras personas, previa escritura de este artículo. Así, en coherencia con un abordaje etnográfico, las categorías de análisis se establecieron a posteriori, con el fin de no sesgar la narración de la anécdota.

Se conoce el uso metodológico de las anécdotas o experiencias en el ámbito de la salud, pero narradas desde la perspectiva clínica del médico que hace la práctica y recibe la presión asistencial, por ejemplo, Espinosa-Brito (2010) y Turabián-Fernández y Pérez-Franco (2015). También se encuentran estudios en inglés que utilizan las anécdotas tanto como método de 
construcción, como método de interpretación para comprender las creencias, percepciones y actitudes de las personas, especialmente en el campo del cuidado de la salud (Hughes \& Huby 2002; Hughes \& Huby 2004).

Espinosa-Brito (2010) aclara de entrada, que le interesa promover el debate entre clínicos, más que entre científicos, como una manera de enfrentar la crítica cientificista de la medicina basada en la evidencia, que juzga objetividad desde las dimensiones de la epidemiología y la bioestadística. Para el caso de la ergonomía y los sistemas de salud, lo más común es encontrar intervenciones y estudios sobre las condiciones de trabajo del personal médico, pero hasta la fecha, no se conocen desde un doble rol "indisoluble" como ergónomopaciente o ergónomo-acudiente.

Turibián Fernández y Pérez Franco (2015) cierran su documento, estableciendo una pista frente a la preocupación de la "objetividad" de estos enfoques metodológicos cualitativo-interpretativos. "Pero, ¿cómo ser objetivo en observaciones, intuiciones y anécdotas subjetivas? Reflexionando y argumentando”.

Fuster (2019) habla de que, en la investigación cualitativa-interpretativa, más precisamente, la fenomenología hermenéutica establece un método riguroso y coherente de las dimensiones éticas cotidianas, opuestas a la obsesión por lo objetivable y que le apuestan a profundizar los aspectos más complejos de la vida humana. Alineados con lo anterior, planteamos viajar desde las anécdotas, como son las experiencias de salud que marcan y transforman la vida y que van por otra dimensión de investigación-comprensión, más allá de los constructos cuantificables. Las anécdotas permiten aprovechar las experiencias vividas para abordarlas sin linealidad y más bien, desde la complejidad de los significados.

Basados en Fuster (2019), las siguientes son las fases del método fenomenológicohermenéutico utilizado:

Etapa previa o clarificación de presupuestos. Valorar la dificultad de estar libre de prejuicios, reconocer que pueden existir presupuestos y preconceptos, pero al mismo tiempo, ponerse en la tarea de exponer el marco teórico, el contexto espacio-temporal, la formación y condición socio-cultural de los sujetos que relatan. Frente a lo anterior, dar respuesta y reconocer el conjunto de actitudes, valores, creencias, intereses y supuestos, entre otros, para estar atentos a que no interfieran en el análisis. En nuestro caso, al asumir los roles indisolubles ergónomo-paciente o ergónomo-acudiente, reconocemos el presupuesto de que entran de manera original el conjunto de actitudes, valores e intereses, entre otros, como investigadores que quieren aportar nuevas formas de abordar la ergonomía y aplicarlas en el caso concreto de los sistemas de salud.

Recoger la experiencia vivida. Es la descripción a manera de anécdotas de las experiencias vividas. Hacer la descripción de una situación vivida en primera persona, hace más directo el acceso a los significados para su posterior reflexión. Se narran las anécdotas en orden cronológico, separando los acontecimientos que requirieron hospitalización de los acontecimientos ambulatorios.

Reflexionar acerca de las anécdotas o experiencias vividas. Al ser dos investigadores en roles distintos, permiten establecer un diálogo reflexivo-situado, a partir de las preguntas 
guía que se establecieron y que permiten la emergencia de categorías explicativas desde la ergonomía, para elaborar significados (comprensión) desde los hechos narrados. La base para esta reflexión fue la construcción de una tabla analítica que incluyó categorías de contexto histórico, aspectos del sistema ergonómico y aspectos del sistema de salud.

Escribir-reflexionar acerca de la experiencia vivida. Es la etapa de integración de todo lo narrado de manera particular en una estructura general, de donde surgieron un grupo de categorías emergentes, con las cuales se responde parcialmente las preguntas de este ejercicio. Es importante aclarar, que la parcialidad de la respuesta a las preguntas no se da por incompletud del trabajo, sino debido a la riqueza inherente del material narrativo, que podría dar origen a otras categorías, dependiendo de la escala y el interés del análisis.

Las tablas 1 y 2 presentan los datos básicos de las anécdotas seleccionadas (situación, duración, lugar, año). A continuación, y a manera de ejemplo, se presentan algunas de las anécdotas, especificando el rol del narrador i.e. como paciente y como acudiente. Entendemos paciente como la persona que adolece de la situación de salud o enfermedad, mientras que por acudiente ${ }^{1}$ nos referimos a la persona que acompaña al paciente, asumiendo los trámites administrativos involucrados y gran parte del cuidado del paciente, incluyendo el apoyo físico, mental y emocional. La escritura fue difícil, porque implicó recordar detalles tal vez olvidados y revivir momentos de dolor. Sin embargo, consideramos que es importante mantener en la narrativa, la fidelidad de las emociones y pensamientos vividos, hasta donde fuera posible.

Tabla 1. Experiencias en hospitalización incluidas en el análisis.

\begin{tabular}{|l|c|c|c|c|}
\hline \multicolumn{1}{|c|}{ Motivo de la hospitalización } & Duración & Lugar & País & Año \\
\hline Atención de parto natural & 3 días & Clínica & Guatemala & 1996 \\
\hline Cesárea & 3 días & $\begin{array}{c}\text { Hospital } \\
\text { universitario }\end{array}$ & Colombia & 1998 \\
\hline Cesárea & 3 días & Clínica especializada & Colombia & 2005 \\
\hline Cirugía por hematoma subdural & 5 días & $\begin{array}{c}\text { Hospital } \\
\text { universitario }\end{array}$ & Colombia & 2014 \\
\hline $\begin{array}{l}\text { Infección urinaria por belactamasas } \\
\text { (BLEE) }\end{array}$ & 14 días & $\begin{array}{c}\text { Hospital } \\
\text { universitario / Casa }\end{array}$ & Colombia & 2016 \\
\hline Tenosinotivis bacteriana en mano & $\mathbf{2 7}$ días & Clínica especializada & Colombia & 2020 \\
\hline
\end{tabular}

Tabla 2. Experiencias en atención ambulatoria incluidas en el análisis.

\begin{tabular}{|l|c|c|c|c|}
\hline Motivo de la consulta & Lugar & Tipo de consulta & País & Año \\
\hline $\begin{array}{l}\text { Tapón de cerumen en un } \\
\text { oído }\end{array}$ & $\begin{array}{c}\text { Consultorio médico } \\
\text { privado }\end{array}$ & $\begin{array}{c}\text { Especializada - } \\
\text { Otorrinolaringología }\end{array}$ & México & 1995 \\
\hline Amigdalitis & $\begin{array}{c}\text { Consultorio médico } \\
\text { privado }\end{array}$ & General & Alemania & 2004 \\
\hline Malestar general & $\begin{array}{c}\text { Consultorio médico } \\
\text { privado }\end{array}$ & General & Alemania & 2004 \\
\hline Control general & $\begin{array}{c}\text { Consultorio en } \\
\text { centro médico EPS }\end{array}$ & General & Colombia & 2008 \\
\hline
\end{tabular}

${ }^{1} \mathrm{El}$ término acudiente es utilizado en Colombia y en Panamá para referirse a la persona que sirve de tutor a uno o varios estudiantes (RAE, 2020). En este artículo se redefine como la persona que acompaña al paciente durante la visita a la institución de salud, le cuida en casa y también realiza los trámites necesarios para procurar la atención del paciente. 


\begin{tabular}{|l|c|c|c|c|}
\hline \multicolumn{1}{|c|}{ Motivo de la consulta } & Lugar & Tipo de consulta & País & Año \\
\hline Reparación dental & $\begin{array}{c}\text { Consultorio } \\
\text { odontológico } \\
\text { privado }\end{array}$ & Odontológica & Alemania & 2011 \\
\hline $\begin{array}{l}\text { Trauma en MMII. Resultó } \\
\text { ser fractura de peroné }\end{array}$ & $\begin{array}{c}\text { Centro de atención } \\
\text { de urgencias de baja } \\
\text { complejidad EPS }\end{array}$ & $\begin{array}{c}\text { General - } \\
\text { Especializada }\end{array}$ & Colombia & 2013 \\
\hline $\begin{array}{l}\text { Seguimiento infección } \\
\text { urinaria }\end{array}$ & $\begin{array}{c}\text { Consultorio en } \\
\text { centro médico EPS }\end{array}$ & $\begin{array}{c}\text { Especializada - } \\
\text { Infectología }\end{array}$ & Colombia & 2017 \\
\hline $\begin{array}{l}\text { Seguimiento por } \\
\text { tenosinovitis bacteriana }\end{array}$ & $\begin{array}{c}\text { Consultorio en } \\
\text { centro médico EPS }\end{array}$ & $\begin{array}{c}\text { Especializada - } \\
\text { Ortopedia }\end{array}$ & Colombia & 2020 \\
\hline
\end{tabular}

Infección urinaria por betalactamasas de espectro extendido (BLEE). Octubre de 2016. Santafé de Bogotá. Clínica universitaria.

Rol de paciente. Estoy seguro de que la bacteria BLEE típica nosocomial, la adquirí en mi estancia en el hospital durante mi primera operación de emergencia, en aquella hospitalización no podía pararme y debía usar el orinal de cama. Llegué a emergencias y nos amaneció esperando atención. Luego de varios exámenes el diagnóstico fue infección urinaria, pero no detectaron de entrada que era una bacteria resistente a los antibióticos. Nunca fui remitido a cama de hospitalización porque no había disponibilidad, así que permanecí en las habitaciones de urgencias, pero una vez detectaron que era una bacteria resistente aplicaron como protocolo que todo el que entrara debería de usar una "bata desechable", pero ante la escasez de ellas, observé que las utilizaban por dos días. Nunca olvidaré el impacto que me causó el circuito cruzado entre la persona encargada de aseo y la persona encargada de dejarme los alimentos. Recuerdo que quien hacía el aseo lo realizaba con un trapero de hilos de algodón pesado y cargado de agua, subió mis pantuflas sobre una escalerilla que se usa para subir a la cama. De repente llegó la alimentación y tuvo que acelerar el aseo, realizándolo superficialmente y saliendo de la habitación. La encargada de la alimentación entró y vio que la mesa auxiliar para comida estaba ocupada con muchas cosas, con rapidez tumbó las pantuflas con su pie y ipuso la bandeja de comida allí, en el peldaño donde estaban las pantuflas! Le tomó un tiempo despejar la mesa y luego recoger la bandeja prácticamente a nivel del suelo, para descargarla sobre la mesa. Se despidió diciéndome, iahí le queda su comida! Estoy seguro de que nunca se realizó aseo a la escalerilla. Finalmente agradecí que saliera pronto por falta de camas y me enviaran a hospitalización domiciliaria.

Oficinas administrativas de la EPS. Rol de acudiente. Llevaba tres horas en el área de atención al público. Estaba lleno y todas las sillas estaban ocupadas, así que decidí sentarme en el piso, recostándome en una pared. ¿Por qué estaba ahí? Por una autorización. Mi esposo estaba hospitalizado desde hacía varios días por una infección urinaria muy resistente y habían probado ya varios antibióticos pero ninguno controlaba la infección. Los médicos querían probar con otro medicamento, pero no estaba incluido en el Plan Obligatorio de Salud (POS). Así que yo debía ir a las oficinas a que lo autorizaran, o si no, no se lo podían aplicar... y el tiempo corría. Pasó un guardia y me regañó por estar sentada en el piso. No me moví. Al pasar nuevamente, y aunque había suficiente espacio para pasar, me golpeó con su bota. Esto fue la gota que derramó el vaso de mi indignación. Lloré, me levanté y me fui a redactar y radicar un derecho de petición. Finalmente aprobaron el medicamento, pero dado 
el riesgo asociado a su utilización y a que, cuando lo aprobaron ya se había logrado controlar temporalmente la infección, ya no se lo aplicaron.

Seguimiento infección urinaria. Septiembre de 2017. Santafé de Bogotá (Colombia). Consultorio de especialistas remitido de la EPS. Rol de paciente.

Después de terminar mi hospitalización domiciliaria y terminar mi tratamiento con antibióticos, fui remitido a seguimiento con especialista en infectología. En la cita, de entrada, seria y malhumorada, la infectóloga revisó mi historia clínica, me preguntó cosas básicas y pasados menos de 10 minutos me recetó nuevos antibióticos. Yo le dije que me sentía muy débil y que mi organismo no aguantaba más antibióticos, que por favor viera alternativas. Altanera me dijo "usted está colonizado y si no se los toma volverá a infectarse". Entonces le dije, así que los antibióticos ahora son recetados como profilaxis. Se enojó conmigo y mi esposa que me acompañó, quien también intentó hacerle ver otras perspectivas de cómo tratarme. Ejerciendo su poder, no nos escuchó y nos sacó prácticamente sin despedirse. Después de este seguimiento dejé todo antibiótico, consulté con un médico privado e inicié un tratamiento alternativo de fortalecimiento inmunológico.

\section{Resultados y discusión}

Las categorías de análisis se establecieron a posteriori, luego de escribir las anécdotas. Dada nuestra cercanía con el enfoque sistémico, consideramos como punto de partida las escalas de análisis propuestas por García-Acosta i.e. el sistema ergonómico y los factores del entorno (2002). Por sistema ergonómico entendemos la relación entre el ambiente construido (espacios físicos y objetos/máquinas) con los seres humanos, en la realización de una actividad o procedimiento concreto. Los factores del entorno hacen referencia a aspectos político-jurídicos, económico-financieros, socioculturales, tecnológico-científicos y ecológicogeográficos que afectan el sistema ergonómico. Es pertinente señalar que el análisis realizado no es exhaustivo, debido a la variedad de circunstancias y contextos. Sin embargo, se registran los elementos más importantes, lo cual nos permite alcanzar el objetivo del trabajo. Dado el propósito del artículo, hicimos énfasis en aspectos de los sistemas de salud, como parte de los aspectos político-jurídicos del entorno.

Las anécdotas fueron organizadas según la severidad de la situación de salud del paciente, iniciando por la más cercana a la muerte (riesgo de hernia cerebral) hasta el monitoreo periódico de la salud (cita de control general). La información proporcionada por las anécdotas fue complementada con una revisión documental sobre asuntos contextuales y técnicos relacionados con las dolencias, procedimientos médicos, instituciones involucradas y sistemas de salud propios de cada país (Becerril-Montekio \& López-Dávila, 2011; GómezDantés, et al., 2011). Con esta información, elaboramos una tabla que permitió relacionar la anécdota con el contexto histórico, algunos aspectos del sistema ergonómico con relación a las instituciones específicas donde se vivió la situación (ver anexo tabla A1), dando respuesta a la pregunta sobre cómo se pueden relacionar el contexto histórico, el sistema ergonómico y el sistema de salud, a partir de la reflexión de las anécdotas.

Respecto a la pregunta central de este trabajo i.e. ¿cómo puede la ergonomía, a partir 
del análisis de estas anécdotas, contribuir a transformar los sistemas de salud? Las siguientes categorías emergieron como algunos de los temas más recurrentes.

Amabilidad, respeto y confianza. La relación entre los profesionales de la salud y el paciente es de "odios y amores". La amabilidad en el trato y el establecimiento de vínculos con los profesionales de la salud afecta radicalmente las actividades con el paciente, mejorando o disminuyendo el bienestar del mismo y el resultado general de todo el sistema. Lo anterior está asociado a la generación de confianza y respeto por parte del paciente, lo cual, a su vez, favorece la actitud del profesional de la salud. Si bien la sobrecarga de trabajo y el estrés que viven los profesionales de la salud inciden sin duda alguna en esta relación, no la justifican. Un paciente está en una situación vulnerable, volviéndose inclusive un objeto de manipulación cuando entra en un quirófano (Hirschauer, 1991). Esto merece una especial comprensión de los profesionales de la salud y podría optimizarse con acciones en los sistemas de trabajo que mejoren las condiciones de los profesionales, para que a su vez aumente su tolerancia y comprensión de los pacientes.

Humanización de la salud. Los sistemas de salud son pensados desde la eficiencia y cobertura del servicio, tanto los que operan bajo la filosofía de aseguradoras privadas, como las que operan como subsidio estatal o cobertura de atención a las enfermedades. Los sistemas de salud pueden ser analizados y diseñados desde perspectivas macroergonómicas, que privilegien las relaciones humanas (confianza y dignidad) entre médico y paciente. Independiente de que sea un tema de debate, la atención en salud desde la promoción y la prevención y más aún, desde la medicina de familia, pueden contribuir a una atención centrada en las personas que conforman un núcleo familiar, de manera que se pueda ver la continuidad cronológica de la condición salud-enfermedad y la continuidad interpersonal y familiar con el sistema de salud.

Innovación social de los procesos con enfoque prospectivo. La humanización de la salud también debe ser vista en la sobrecarga de los profesionales de la salud que integran especialmente los servicios de urgencia. La atención de urgencias genera muchas sobrecargas y decisiones erradas por actuar bajo presión. Estudios sobre la toma de decisiones en la atención clínica en donde se ponen en la balanza la medicina basada en la evidencia con respecto a influencias de contexto, entre otros, demuestran la importancia metodológica del trabajo desde las anécdotas, ya sean reales o como escenarios prospectivos de personificación (Dharmaratne et al., 2015). Se requiere innovación de procesos con equipos multidisciplinarios en donde el ergónomo organizacional, con su formación desde el enfoque de sistemas, construya modelos de atención bajo escenarios prospectivos, más eficaces y humanos, que incluso valoren situaciones similares a la pandemia Covid 19, que tomó por sorpresa a la mayoría de los sistemas de salud.

Aseo y limpieza. Procesos básicos pero vitales. Los procedimientos de limpieza y desinfección son críticos, pero el personal encargado parece no ser consciente de ello. Esto puede estar asociado al nivel educativo de quienes lo realizan. En cualquier caso, sería posible capacitarlos y explicarles cuán importante es su trabajo para que todo funcione correctamente. También está relacionado con la humanización, pero en este caso dentro de la misma institución y con relación a la vida cotidiana del personal. Los protocolos de bioseguridad implican nuevos retos no solo en procedimientos, sino en el diseño de nuevos 
dispositivos médicos que eliminen la incertidumbre frente a "los enemigos microscópicos" cada vez más resistentes y mutantes.

A mayor especialización, mejor organización. Las áreas especializadas parecen estar mejor organizadas que las generales. Conforme "subíamos de nivel" i.e. aumentaba la criticidad de la situación, las condiciones mejoraron y los procesos fluían mejor. Los espacios de atención de urgencias son los más críticos en sistemas de salud que no han trabajado la promoción y la prevención. La clasificación por triage es necesaria, pero no suficiente, se pueden pensar nuevas formas de flujo de atención, en donde el respaldo de tecnologías, sistemas Tics orientados a la telemedicina y nuevos dispositivos médicos, aceleren prediagnósticos y la clasificación genere bifurcaciones de atención y no embudos, como actualmente ocurre.

Actuar con incertidumbre científica. La sincronía en la ejecución de procedimientos es clave para aumentar las posibilidades de éxito de las intervenciones del sistema. Los profesionales de la salud deben tomar decisiones rápidas y actuar, con la información que tengan, como con las experiencias adquiridas. En este contexto, varios aspectos generan asincronías. Algunos son de tipo técnico-científico, como el tiempo requerido para tener los resultados de un análisis bacteriológico. Otros, sin embargo, son de tipo administrativo, como la autorización de un medicamento no contemplado en el plan de salud. La ergonomía de concepción puede ayudar a crear un banco de casos clínicos en línea y disponible para todo el sistema de salud, con alta usabilidad. La inteligencia artificial, la minería de datos y los bloques de datos (Blockchain), entre otros, ayudarán a gestionar mejor la incertidumbre.

Los valores como determinantes del diseño del sistema de salud. En esta categoría es posible comparar dos países: Colombia y Alemania. El sistema de salud alemán es altamente distribuido, opera verdaderamente como red de servicios médicos con multinodos y dicha diversificación de nodos de atención involucra a todos los profesionales, sin discriminación ni exclusión, y todas las áreas de la salud, lo que diversifica y distribuye la atención, evitando cuellos de botella y demoras para establecer citas y procedimientos. El valor clave es la solidaridad. Por el contrario, el sistema de salud colombiano solo nominalmente es llamado red, pero en realidad es una suerte de empresas (EPS) que maneja una lista de prestadores de servicios de salud limitada a vigencia de contratos. Una EPS opera como cualquier empresa financiera, con proveedores determinados y no con nodos diversos y universales tanto de instituciones, como de profesionales, lo que deriva en falta de atenciones o atenciones con retrasos de meses para citas con especialistas, procedimientos y terapias. Dicha ineficiencia es resaltada con las innumerables quejas, derechos de petición, tutelas y demandas que se compilan desde la defensoría del pueblo (Defensoría del Pueblo, 2020), se presentan ante un juez de la República y se tramitan frente a las EPS. En el 2019, en Colombia se presentó una tutela para proteger los derechos a la salud cada 2,5 minutos (El Tiempo, 2020, 24 de julio).

¿Conocimiento o ignorancia? El conocimiento (y en su defecto, la ignorancia) influyen radicalmente en la actitud y la experiencia de la atención médica. Como paciente, resulta casi contraproducente ser experto en ergonomía o en medicina, porque es muy difícil dejar de analizar las situaciones e identificar problemas en las diferentes escalas del sistema de salud. Así, al detectar problemas, se pierde confianza en el sistema, en especial en los equipos de trabajo, lo cual genera dos consecuencias. Por un lado, el paciente necesita estar tranquilo 
para recuperarse. Al no estar tranquilo por la detección de errores y la impotencia de hacer algo para corregirlos, aumenta su estrés, afectando negativamente su recuperación. Por el otro lado, los profesionales de la salud, en especial los médicos, necesitan sentir que sus pacientes confían en ellos. Esta situación fue analizada en otra investigación, en donde el ortopedista entrevistado señalaba la dicotomía sobre operar o no a un adolescente, cuya familia le expresó su desconfianza con la institución (Lange-Morales, 2017). En principio, debería favorecerse el conocimiento de procedimientos y tratamientos, sobre su desconocimiento. Sin embargo, este conocimiento debe estar soportado por procesos que acerquen lo real al ideal. En otras palabras, es mejor que todos los involucrados (incluyendo pacientes y acudientes) tengan un mayor conocimiento sobre los procedimientos médicos, siempre y cuando dichos procedimientos sucedan lo más cercano a lo que está establecido como lo óptimo. Una manera de contribuir a lograr lo anterior desde la ergonomía es mediante el análisis de procesos de trabajo a través de enfoques participativos que ayuden a los equipos de trabajo a detectar desviaciones a tiempo, antes de que el paciente se dé cuenta o sufra las consecuencias. Inclusive, dependiendo del nivel de conocimiento del paciente, este podría ser incorporado al sistema como un vigía adicional. El reconocer su conocimiento, en vez de negárselo o regañarlo por opinar o señalar un problema, aumentaría la confianza del paciente experto, incidiendo positivamente en su recuperación.

Aumento de carga cognitiva en el uso de dispositivos médicos. Hay una gran necesidad de diseño y desarrollo de dispositivos médicos para mejorar los procesos asociados. En particular se destacan las bombas de infusión y los elementos para la venoclisis. La usabilidad de las bombas de infusión es crítica, las auxiliares de enfermería se estresan y terminan peleando y de mal genio por dicho aparato. Las señales sonoras pensadas como componente de fiabilidad del buen funcionamiento del dispositivo aumentan la ansiedad tanto de pacientes, como de las enfermeras y auxiliares. Están diseñadas para que paren y activen alarmas en modo de fallos, en condiciones muy sensibles, independientemente de un buen mantenimiento preventivo. La hipersensibilidad frente a cualquier mínimo fallo en el estado del funcionamiento, bloquea el aparato de manera inmediata y automática. Con los avances en inteligencia artificial (IA) el aparato podría tener protocolos autónomos de desbloqueo en fallos sencillos como cambios de presión, burbujas de aire, entre otros, eliminando del auxiliar de enfermería la acción y la responsabilidad de una serie de operaciones que se pueden automatizar.

Responsabilidad del médico versus responsabilidad del equipo y del sistema. La comprensión de la responsabilidad como asunto del médico (o del encargado del proceso) versus asunto del sistema o del equipo es otra categoría de suma importancia, afectando negativamente la oportunidad de mejoramiento del sistema. Al presentarse una queja al sistema (mediante PQRS, por ejemplo), la administración remite el problema al médico o jefe responsable. Esto hace que el médico perciba la queja como personal, en vez de revisar y actuar como equipo. Aunado a lo anterior, la rotación de turnos hace que se trabaje con diferentes personas y no necesariamente se sientan como parte de un mismo equipo, cuyo resultado final depende de la sincronía, la empatía y la calidad de todas. Si lo vemos desde la ergonomía, la responsabilidad no es solo de las personas (el equipo humano), sino de todos los elementos que conforman el sistema ergonómico, así como de todos los equipos de 
trabajo que soportan los procesos. Para mejorar el sistema de salud, es necesario que se comprendan y actúen como sistema.

Certificaciones versus realidades. Una de las contribuciones más importantes que hace la ergonomía a la comprensión de trabajo es la distinción entre lo pre-escrito y lo real. En los procedimientos llevados a cabo en una institución de salud este tema resulta de especial atención. Previo a prestar un determinado servicio, las instituciones deben certificarse en dicho servicio, lo cual implica el diligenciamiento de una serie de formatos y requerimientos, que dan cuenta de la medición y el control de un momento histórico determinado. Sin embargo, la realidad puede distar mucho de lo real, ya que la calidad no es un asunto de formatos y procedimientos donde se registró el cumplimiento en el momento de la certificación. La calidad es una actitud que las personas incorporan y viven diariamente. Si no es así, las certificaciones son letra muerta (colgada en los muros). La aplicación de la ergonomía en sus diferentes dominios podría aumentar a la eficacia del sistema de salud, evitando peligros y reduciendo riesgos, incidentes, accidentes y muertes.

\section{Conclusiones}

Como lo plantea Sebastián-Cárdenas (2014), la ergonomía necesita sacudirse del realismo ingenuo ateórico, por tanto, requiere del desarrollo de métodos que fortalezcan la perspectiva construccionista. La ergonomía no puede seguir siendo reducida a los análisis ergonómicos excesivamente simplificados y, sobre todo, delimitados a la dimensión física.

Las anécdotas han sido sistemáticamente marginadas de la investigación por la preocupación de que no se pueden establecer generalizaciones a partir de uno o unos cuantos casos contados desde las subjetividades de los individuos, desde lo particular y lo específico y, por tanto, no pueden contribuir al "desarrollo de la ciencia" y se consideran pseudo investigación porque no pueden aportar a la generalización y a la solidificación de determinadas teorías. Lo anterior se puede verificar en el diálogo entre Laura y Helen (Castañeda-Gutiérrez \& Gutiérrez-Ríos, 2017). Sin embargo, lo que se ha visto es que de las anécdotas se pueden deducir aprendizajes significativos y contribuyen por tanto al conocimiento, la comprensión y la transformación de situaciones, en nuestro caso, los sistemas de salud.

De la reflexión sobre las anécdotas fue posible inferir conocimiento que, desde la ergonomía, puede contribuir a mejorar los sistemas de salud: relación entre la amabilidad, el respeto y la confianza; la humanización de la salud; innovación social de los procesos con enfoque prospectivo; la importancia de los procesos de apoyo; mayor organización en los servicios de urgencias; la creación de sistemas de información inteligentes que reduzcan incertidumbre en la toma de decisiones de los profesionales de la salud; la importancia de los valores como determinantes del diseño de los sistemas de salud; la necesidad de extender el conocimiento y el trabajo como equipo, incluyendo pacientes y acudientes; la importancia del diseño de los dispositivos médicos para reducir carga cognitiva; el papel de la responsabilidad personal y distribuida; y la discrepancia entre las certificaciones (llevadas a lo pre-escrito) y los desempeños reales. 


\section{Referencias}

Banchs R. M. A. (2007). Entre la ciencia y el sentido común: representaciones sociales y salud. En T. Rodríguez Salazar \& M. L. García Curiel (coords.), Representaciones sociales: Teoría e investigación (pp. 219-254). Editorial CUCSH-UDG.

Becerril-Montekio, V., \& López-Dávila, L. M. (2011). Sistema de salud de Guatemala. Salud Pública de México, 53(supl 2), S197-S208. http://www.scielo.org.mx/pdf/spm/v53s2/15.pdf

Castañeda-Gutiérrez, L. D., \& Gutiérrez-Ríos, M. Y. (2017). Un diálogo sobre el tipo de estudio de caso como un tipo de investigación. Oralidad-es, 3(6), 48-52. https://revistaoralidades.com/index.php/ro-es/article/view/86

Defensoría del Pueblo (2020). La tutela y los derechos a la salud y a la seguridad social 2019. https://www.defensoria.gov.co/es/nube/noticias/9479/La-tutela-y-los-derechos-a-la-saludy-a-la-seguridad-social-14\%C2\%Bo-edici\%C3\%B3n-tutela-informe-Defensor\%C3\%ADa.htm

Dharmaratne, S., Razee H., Ponnamperuma G., Marambe K., Dawson A. \& Balasooriya C. (2015). Vignette-based decision point analysis (VDPA): A novel method of exploring person-centered contextual influences on clinical decision-making. European Journal for Person Centered Healthcare, 3(2), 151-157. https://doi.org/10.5750/ejpch.v3i2.902

El Tiempo (2020, 24 de julio). Tutelas por salud en el 2019 según informe de la defensoría del pueblo. https://www.eltiempo.com/salud/tutelas-por-salud-en-el-2019-segun-informe-dela-defensoria-del-pueblo-521682

Espinosa-Brito, A. D. (2010) Enfermedades infecciosas agudas y respuestas inmunológicas. Algunas anécdotas sobre la práctica clínica a propósito de la pandemia de Influenza A (H1N1). Medisur, 8(1), 53-59. http://www.redalyc.org/articulo.oa?id=180020057011

Fuster, D. E. G. (2019). Investigación cualitativa: Método fenomenológico hermenéutico. Monográfico: Avances en investigación cualitativa en educación, 7(1), 201-229. https://doi.org/10.20511/pyr2019.v7n1.267

García-Acosta, G. (2002). La ergonomía desde la visión sistémica. Unibiblos.

Gómez-Dantés, O., Sesma, S., Becerril, V. M., Knaul, F. M., Arreola, H., \& Frenk, J. (2011). Sistema de salud de México. Salud Pública de México, 53(supl 2), S220-S232. http://www.scielo.org.mx/pdf/spm/v53s2/17.pdf

Hirschauer, S. (1991). The Manufacture of Bodies in Surgery. SAGE.

Hughes, R., \& Huby, M. (2002). The application of vignettes in social and nursing research. Journal of Advanced Nursing, 37(4), 382-386. https://doi.org/10.1046/j.13652648.2002.02100.x

Hughes, R., \& Huby, M. (2004). The construction and interpretation of vignettes in social research. Social Work \& Social Sciences Review, 11(1), 36-51. https://doi.org/10.1921/17466105.11.1.36

Lange-Morales, K. (2017). Compatibilidades en las multiplicidades: El uso de dispositivos médicos en sala de operaciones [tesis doctoral, Universidad Nacional de Colombia]. Repositorio Institucional UN. https://repositorio.unal.edu.co/handle/unal/59321

Sebastián-Cárdenas, M. L. (2014). Hacia una perspectiva construccionista de la ergonomía: Aplicaciones de la narrativa en ergonomía (prevención y diseño). Apuntes de Psicología, 32(3), 199-215. https://hdl.handle.net/11441/85130

Turabián-Fernández, J. L., \& Pérez-Franco, B. (2015). Observaciones, intuiciones y anécdotas, desde la perspectiva del médico, para una teoría de la historia natural de la continuidad interpersonal. Los colores del tiempo. Revista Clínica Médica Familiar 8(2), 125-136. http://www.redalyc.org/articulo.oa?id=169641406006 
Wilks, T. (2004). The use of vignettes in qualitative research into social work values. Qualitative Social Work, 3(1), 78-87. https://doi.org/10.1177/1473325004041133 


\section{Anexo}

Tabla A1. Análisis de anécdotas desde un enfoque sistémico.

\begin{tabular}{|c|c|c|c|c|}
\hline $\begin{array}{l}\text { Propósito del } \\
\text { uso del sistema }\end{array}$ & Acontecimiento analizado & Contexto histórico & $\begin{array}{c}\text { Algunos aspectos del sistema } \\
\text { ergonómico }\end{array}$ & $\begin{array}{l}\text { Aspectos relacionados con el } \\
\text { sistema de salud }\end{array}$ \\
\hline $\begin{array}{l}\text { Evitar una hernia cerebral (y } \\
\text { por tanto un coma o muerte en } \\
\text { corto plazo) }\end{array}$ & $\begin{array}{l}\text { Atención de hematoma subdural. } \\
\text { Requirió hospitalización por cinco } \\
\text { días. }\end{array}$ & \begin{tabular}{|l|} 
\\
\\
\\
Bogotá, Colombia. 2014. El hospital \\
fue fundado en 1942. Con proyectos \\
de infraestructura y renovación \\
tecnológica permanente es su plan \\
de acción. En 2014, varios hospitales \\
grandes se encuentran cerrados. La \\
EPS tiene una limitada red de \\
atención de IPS. \\
\\
\end{tabular} & $\begin{array}{l}\text { Área de espera de pacientes } \\
\text { sobresaturada y sin disponibilidad de } \\
\text { asientos para tantos pacientes. A pesar } \\
\text { del triage, la decisión de la prioridad de la } \\
\text { atención al interior del área de } \\
\text { emergencia termina dándose por los } \\
\text { pacientes que más se quejan y que son } \\
\text { más impertinentes o desesperados. } \\
\text { Asincronía en el uso del equipo de } \\
\text { radiología y diagnóstico del evento en } \\
\text { emergencias, la decisión organizacional } \\
\text { es dilatar el tiempo entre la toma de la } \\
\text { radiografía y el diagnóstico en por lo } \\
\text { menos cinco horas, lo que puede ser fatal } \\
\text { para una emergencia médica como la } \\
\text { descrita. Disponibilidad inmediata de } \\
\text { sala de operaciones y dispositivos } \\
\text { médicos para atención de cuarto nivel } \\
\text { (neurocirugía), superado el embudo de } \\
\text { urgencias, las decisiones de operación } \\
\text { entran a un circuito más organizado. Sala } \\
\text { post-operatoria comunitaria y fila de } \\
\text { espera para cama de hospitalización } \\
\text { compartida. Se forma un nuevo embudo } \\
\text { por la falta de camas de hospitalización y } \\
\text { la carga y afectación emocional la cargan } \\
\text { los pacientes convalecientes. Médicos } \\
\text { generales en turno de emergencia. En } \\
\text { operación: Dos neurocirujanos, uno de } \\
\text { ellos en residencia y una anestesióloga, } \\
\text { junto con enfermeras, instrumentistas y } \\
\text { auxiliares. }\end{array}$ & $\begin{array}{l}\text { le } \\
\text { Cobertura de acuerdo con ley 10o de } 1993 \text {. } \\
\text { Cotizante como empleado público a una } \\
\text { Empresa Prestadora de Servicios de Salud } \\
\text { (EPS), al día y con acceso al plan obligatorio } \\
\text { de salud (POS). Paciente atendido en un } \\
\text { hospital universitario de cuarto nivel como } \\
\text { IPS de la red hospitalaria y cerca del lugar de } \\
\text { trabajo. } \\
\end{array}$ \\
\hline
\end{tabular}


EID Ergonomía, Investigación y Desarrollo, 3(2), 2021, 52-64

\begin{tabular}{|c|c|c|c|c|}
\hline $\begin{array}{l}\text { Propósito del } \\
\text { uso del sistema }\end{array}$ & Acontecimiento analizado & Contexto histórico & $\begin{array}{c}\text { Algunos aspectos del sistema } \\
\text { ergonómico }\end{array}$ & $\begin{array}{l}\text { Aspectos relacionados con el } \\
\text { sistema de salud }\end{array}$ \\
\hline $\begin{array}{l}\text { Controlar o eliminar una } \\
\text { infección sistémica }\end{array}$ & \begin{tabular}{|lrr} 
Infección & urinaria & \multicolumn{1}{c}{ por } \\
betalactamasas & de & espectro \\
extendido & (BLEE). & Requirió \\
hospitalización por 14 días, la mitad & en la clínica y la mitad domiciliaria.
\end{tabular} & $\begin{array}{l}\text { Bogotá, Colombia. 2016. La clínica } \\
\text { fue fundada en 1977 y estaba } \\
\text { iniciando su proceso de disolución y } \\
\text { liquidación, por desfase entre pagos } \\
\text { que le debían las EPS y los pagos } \\
\text { que deberían hacer a sus } \\
\text { proveedores. Mínima selección por } \\
\text { parte de usuarios de acceso a } \\
\text { hospitales, por la limitación de la } \\
\text { red de IPS que maneja la EPS. }\end{array}$ & $\begin{array}{l}\text { Atención de lugar de urgencias con un } \\
\text { triage real de tiempos muy prolongado } \\
\text { (horas) por la saturación de pacientes. } \\
\text { Disponibilidad insuficiente de camillas, } \\
\text { solo sillas reclinables en urgencias. Las } \\
\text { decisiones de atención se ven alteradas y } \\
\text { limitadas por falta de infraestructura, } \\
\text { mobiliario y organización del personal. } \\
\text { No disponibilidad de camas de } \\
\text { hospitalización, permanencia en } \\
\text { emergencia, se establece tratamiento con } \\
\text { antibióticos. Las decisiones de mi } \\
\text { atención y tratamiento se concentran en } \\
\text { pocos médicos. Existencia de laboratorio } \\
\text { clínico para definición del diagnóstico. } \\
\text { Las condiciones de aislamiento y } \\
\text { adecuados manejos de protocolos de } \\
\text { bioseguridad no se cumplen por las } \\
\text { presiones del momento y día a día. Porta } \\
\text { venoclisis, equipo de venoclisis y buretrol } \\
\text { con regulación manual y por gravedad. } \\
\text { Atendido principalmente por auxiliares } \\
\text { de enfermería y por médico del turno de } \\
\text { emergencias, esporádicamente por } \\
\text { internista encargado. Las urgencias son } \\
\text { un cuello de botella, pero tienen toda la } \\
\text { carga cognitiva por ser la primera línea } \\
\text { para salvar vidas. El sistema } \\
\text { organizacional de las IPS, toma } \\
\text { decisiones sin esta condición y sin pensar } \\
\text { en un enfoque sistémico. }\end{array}$ & $\begin{array}{l}\text { le } \\
\text { Cobertura de acuerdo con ley 1oo de } 1993 \text {. } \\
\text { Cotizante como empleado público a una } \\
\text { Empresa Prestadora de Servicios de Salud } \\
\text { (EPS), al día y con acceso al plan obligatorio } \\
\text { de salud (POS). Paciente atendido en una } \\
\text { clínica universitaria, que pasó a disolución y } \\
\text { liquidación en el año 2018 y finalizó en } \\
\text { 2019, por acreencias como IPS de la red } \\
\text { hospitalaria. Estaba ubicada cerca del lugar } \\
\text { de vivienda del paciente. }\end{array}$ \\
\hline $\begin{array}{l}\text { Controlar o eliminar una } \\
\text { infección sistémica }\end{array}$ & $\begin{array}{l}\text { Tenosinotivis bacteriana en mano. } \\
\text { Requirió } 27 \text { días de hospitalización. }\end{array}$ & $\begin{array}{l}\text { Bogotá, Colombia. } 2020 . \\
\text { Inicialmente fundada a finales de los } \\
\text { años 50 por una congregación } \\
\text { religiosa. Refundada en el año } 2013 \\
\text { como clínica privada, que se ha ido } \\
\text { enfocando en pacientes de alta } \\
\text { complejidad. Para el 2020 se dio } \\
\text { inicio de pandemia por COVID 19. } \\
\text { Fue la alternativa para ser atendido, } \\
\text { sin posibilidad de selección por } \\
\text { urgencia. Durante la estancia de } \\
\text { atención se estaban iniciando obras } \\
\text { de expansión. }\end{array}$ & \begin{tabular}{|l} 
Unidad de cuidado intermedio \\
preoperatorio, con 15 camas con baños \\
compartidos. La atención casi simultánea \\
de las auxiliares de enfermería y la poca \\
luz generaban muchos fallos y \\
sufrimientos en la colocación de \\
venoclisis. Habitación de aislamiento \\
hospitalario por patología infecciosa con \\
baño privado. Cama hospitalaria de \\
posiciones ajustables totalmente \\
funcional, mesa de comida, mesa de \\
noche y sillas de visita. Contenedores de \\
desechos para agujas, para gasas y varios. \\
Dispositivo médico de bomba de infusión \\
\end{tabular} & $\begin{array}{l}\text { Cobertura de acuerdo con ley } 100 \text { de } 1993 \text {. } \\
\text { Cotizante como empleado público a una } \\
\text { Empresa Prestadora de Servicios de Salud } \\
\text { (EPS), al día y con acceso al plan obligatorio } \\
\text { de salud (POS). Paciente atendido en una } \\
\text { clínica particular, como IPS de la red } \\
\text { hospitalaria, pero ubicada lejos de su casa } \\
\text { (más de una hora). }\end{array}$ \\
\hline
\end{tabular}


EID Ergonomía, Investigación y Desarrollo, 3(2), 2021, 52-64

ISSN 2452-4859

\begin{tabular}{|c|c|c|c|c|}
\hline $\begin{array}{l}\text { Propósito del } \\
\text { uso del sistema }\end{array}$ & Acontecimiento analizado & Contexto histórico & $\begin{array}{c}\text { Algunos aspectos del sistema } \\
\text { ergonómico }\end{array}$ & $\begin{array}{l}\text { Aspectos relacionados con el } \\
\text { sistema de salud }\end{array}$ \\
\hline & & & $\begin{array}{l}\text { que permanentemente fallaba, a pesar de } \\
\text { que se cambió por lo menos tres veces, lo } \\
\text { contradictorio de la bomba de infusión es } \\
\text { que debería ser un dispositivo que } \\
\text { reduzca la carga del personal médico y } \\
\text { aumente la confianza y el relajamiento de } \\
\text { los pacientes (todo el tiempo se activaron } \\
\text { alarmas sonoras). También se tienen } \\
\text { dispositivos médicos para verificación de } \\
\text { signos vitales de rotación y punto de } \\
\text { oxígeno por red todos ellos en adecuadas } \\
\text { condiciones funcionales. Porta venoclisis, } \\
\text { equipo de venoclisis y buretrol con } \\
\text { regulación manual y por gravedad, que } \\
\text { terminó reemplazando la bomba de } \\
\text { infusión, pero que implicó atención } \\
\text { permanente por parte del paciente y } \\
\text { acudiente, y luego por enfermera } \\
\text { particular contratada por la acudiente. } \\
\text { Timbre de llamada sin señalizar, que no } \\
\text { permitía respuesta inmediata por parte } \\
\text { de las auxiliares de enfermería. Personal } \\
\text { médico: Cirujano ortopedista, internista } \\
\text { jefe, médicos hospitalarios, enfermeros } \\
\text { jefe, auxiliares de enfermería, } \\
\text { infectólogos en rotación y terapeutas en } \\
\text { rotación. Las principales contradicciones } \\
\text { y dificultades en la toma de decisiones } \\
\text { sobre el tratamiento se derivaron } \\
\text { básicamente en no contar a tiempo con } \\
\text { resultados de los laboratorios de } \\
\text { hemocultivos (4 a } 5 \text { días), no por } \\
\text { negligencia sino por la velocidad de } \\
\text { generación de la colonización bacteriana } \\
\text { y por la no inclusión de ciertos } \\
\text { antibióticos en el esquema de cobertura } \\
\text { de la EPS. }\end{array}$ & \\
\hline
\end{tabular}


EID Ergonomía, Investigación y Desarrollo, 3(2), 2021, 52-64

\begin{tabular}{|c|c|c|c|c|}
\hline $\begin{array}{l}\text { Propósito del } \\
\text { uso del sistema }\end{array}$ & Acontecimiento analizado & Contexto histórico & $\begin{array}{c}\text { Algunos aspectos del sistema } \\
\text { ergonómico }\end{array}$ & $\begin{array}{l}\text { Aspectos relacionados con el } \\
\text { sistema de salud }\end{array}$ \\
\hline \multirow[t]{2}{*}{ Atención de un parto } & $\begin{array}{l}\text { Parto normal. Tres días de } \\
\text { hospitalización. }\end{array}$ & $\begin{array}{l}\text { Guatemala, Guatemala, } 1996 . \\
\text { Clínica privada. No hay cobertura } \\
\text { universal en salud, las personas que } \\
\text { no laboran no tienen acceso } \\
\text { subsidiado. La constitución de } \\
\text { Guatemala declara que la Salud es } \\
\text { un bien público y que todas las } \\
\text { personas e instituciones deben velar } \\
\text { por su conservación y restitución. }\end{array}$ & $\begin{array}{l}\text { Sala de operaciones de clínica } \\
\text { especializada en partos. } \\
\text { Equipo quirúrgico médico completo } \\
\text { (ginecólogo, pediatra y anestesiólogo). } \\
\text { Ante la disyuntiva de continuar con parto } \\
\text { normal por la posible presencia de una } \\
\text { circular (cordón umbilical enrollado en el } \\
\text { cuello del feto), el uso de un } \\
\text { fonendoscopio resulta decisivo para que } \\
\text { los médicos decidan continuar con parto } \\
\text { normal. Evitan la utilización de fórceps, } \\
\text { haciendo una maniobra de Kristeller. Ni } \\
\text { el acudiente ni la paciente saben de dicha } \\
\text { maniobra, ni son consultados. Hay total } \\
\text { confianza en los médicos. } \\
\end{array}$ & $\begin{array}{l}\text { Paciente no cubierta por el Instituto } \\
\text { Guatemalteco de Seguridad Social (IGSS) } \\
\text { por no tener un contrato formal de trabajo, } \\
\text { pero con medios económicos suficientes } \\
\text { para acceder al sistema de salud del sector } \\
\text { privado para este tipo de atención de la } \\
\text { salud. }\end{array}$ \\
\hline & $\begin{array}{l}\text { Cesárea programada. Tres días de } \\
\text { hospitalización. }\end{array}$ & $\begin{array}{l}\text { Bogotá, Colombia.1998. El hospital } \\
\text { fue fundado en 1977, en aquel } \\
\text { momento dicha IPS estaba en } \\
\text { adecuado funcionamiento y sin } \\
\text { problemas financieros, pues la ley } \\
\text { 100 apenas llevaba } 5 \text { años en } \\
\text { aplicación. }\end{array}$ & $\begin{array}{l}\text { La realización de ecografías en cada } \\
\text { trimestre del embarazo permite la } \\
\text { identificación de una circular. Si bien una } \\
\text { circular puede ser riesgosa a la hora del } \\
\text { parto, no es motivo per se para decidir } \\
\text { practicar una cesárea. Sin embargo, como } \\
\text { es un hospital universitario, podría } \\
\text { favorecerse la realización de cesáreas } \\
\text { para tener más posibilidades de enseñar a } \\
\text { los estudiantes, lo cual efectivamente } \\
\text { sucede en el caso de análisis. Por tanto, } \\
\text { esta intervención quirúrgica es también } \\
\text { un taller de enseñanza - aprendizaje. } \\
\end{array}$ & $\begin{array}{l} \\
\text { Cobertura de acuerdo con ley 10o de } 1993 \text {. } \\
\text { Cotizante como independiente a una } \\
\text { Empresa Prestadora de Servicios de Salud } \\
\text { (EPS), al día y con acceso al plan obligatorio } \\
\text { de salud (POS). Paciente atendida como } \\
\text { beneficiaria del cotizante, en una clínica } \\
\text { universitaria como IPS de la red hospitalaria } \\
\text { y cerca de su lugar de vivienda. }\end{array}$ \\
\hline Atención de un parto & $\begin{array}{l}\text { Cesárea no programada. Tres días de } \\
\text { hospitalización. }\end{array}$ & $\begin{array}{l}\text { Bogotá, Colombia. 2005. Metrópolis } \\
\text { de siete millones de habitantes. La } \\
\text { clínica es muy pequeña y fue creada } \\
\text { no más de } 5 \text { años antes del evento. } \\
\text { Sólo era para embarazos y partos } \\
\text { complicados. Hoy día extendió su } \\
\text { capacidad de atención. Sin } \\
\text { embargo, la red de IPS que prestan } \\
\text { servicios con la EPS a la cual cotiza } \\
\text { la paciente ha disminuido. }\end{array}$ & $\begin{array}{l}\text { La toma de decisiones sobre dónde se } \\
\text { realizará el nacimiento cambia gracias a } \\
\text { una intervención de tipo legal (derecho } \\
\text { de petición). Clínica con áreas } \\
\text { especializadas y dotadas con todo lo } \\
\text { necesario para atender partos de alta } \\
\text { complejidad. La atención a la paciente en } \\
\text { la clínica final fluye sin problemas. }\end{array}$ & $\begin{array}{l}\text { Cobertura de acuerdo con ley } 100 \text { de } 1993 \text {. } \\
\text { Paciente es empleado público y segundo } \\
\text { cotizante afiliado una Empresa Prestadora } \\
\text { de Servicios de Salud (EPS), al día y con } \\
\text { acceso al plan obligatorio de salud (POS). } \\
\text { Paciente atendida en una clínica } \\
\text { especializada como IPS de la red hospitalaria } \\
\text { y cerca de su lugar de vivienda, pero } \\
\text { después de meter un derecho de petición. } \\
\text { Originalmente había sido remitida a una } \\
\text { clínica a dos horas de su hogar. }\end{array}$ \\
\hline
\end{tabular}




\begin{tabular}{|c|c|c|c|c|}
\hline $\begin{array}{l}\text { Propósito del } \\
\text { uso del sistema }\end{array}$ & Acontecimiento analizado & Contexto histórico & $\begin{array}{c}\text { Algunos aspectos del sistema } \\
\text { ergonómico }\end{array}$ & $\begin{array}{l}\text { Aspectos relacionados con el } \\
\text { sistema de salud }\end{array}$ \\
\hline $\begin{array}{l}\text { Atención de una situación no } \\
\text { vital con consecuencias graves si } \\
\text { no se atendía }\end{array}$ & $\begin{array}{l}\text { Atención de accidente en miembro } \\
\text { inferior. Atención ambulatoria. }\end{array}$ & \begin{tabular}{|l|} 
Bogotá, Colombia. 2013. Metrópolis \\
de siete millones de habitantes. \\
Centro de Atención en Salud, de \\
Complejidad Baja perteneciente a la \\
Caja de Compensación Familiar, que \\
a su vez pertenece a la red de IPS. \\
En dicho centro se atienden \\
emergencias para ser remitidos a \\
otros centros que traten situaciones \\
de mayor complejidad.
\end{tabular} & $\begin{array}{l}\text { La paciente, debido a su conocimiento } \\
\text { sobre el tema y para no alterar vacaciones } \\
\text { familiares, decide que no es urgente } \\
\text { acudir al sistema, corriendo el riesgo de } \\
\text { un desplazamiento del hueso fracturado. } \\
\text { La IPS cuenta con los servicios } \\
\text { diagnósticos necesarios para atender } \\
\text { urgencias de baja complejidad. Hay } \\
\text { sincronía en la realización de exámenes } \\
\text { diagnósticos (radiografía) y su lectura, lo } \\
\text { que permite acción inmediata de los } \\
\text { profesionales de la salud e inmovilizan la } \\
\text { fractura. El proceso fluye con } \\
\text { normalidad. }\end{array}$ & $\begin{array}{l}\text { Cobertura de acuerdo con ley } 100 \text { de } 1993 \text {. } \\
\text { Paciente es empleado público y segundo } \\
\text { cotizante afiliado una Empresa Prestadora } \\
\text { de Servicios de Salud (EPS), al día y con } \\
\text { acceso al plan obligatorio de salud (POS). La } \\
\text { atención sucede en una IPS de la red } \\
\text { hospitalaria relativamente cerca de su lugar } \\
\text { de vivienda, dedicada a atender urgencias de } \\
\text { baja complejidad. }\end{array}$ \\
\hline \multirow[t]{2}{*}{$\begin{array}{l}\text { Control de la evolución de } \\
\text { situaciones críticas ya atendidas }\end{array}$} & $\begin{array}{l}\text { Seguimiento a infección urinaria. } \\
\text { Atención ambulatoria. }\end{array}$ & \begin{tabular}{|l|} 
\\
\end{tabular} & $\begin{array}{l}\text { Consultorio con elementos y dispositivos } \\
\text { médicos típicos, escritorio, computador, } \\
\text { sistema especializado de software } \\
\text { (historia clínica), camilla y baño privado. } \\
\text { Personal médico: solo la especialista en } \\
\text { infectología. La decisión del tratamiento } \\
\text { la basó únicamente en la historia clínica, } \\
\text { no remitió a nuevos exámenes clínicos } \\
\text { para confirmar diagnóstico. La } \\
\text { interacción de la especialista fue mínima, } \\
\text { se concentró frente a la pantalla del } \\
\text { computador. La toma de decisiones de la } \\
\text { especialista no es colegiada, ni tampoco } \\
\text { es comparada, lo que la vuelve } \\
\text { prácticamente una imposición, pues el } \\
\text { paciente no tiene opción de un } \\
\text { diagnóstico y tratamiento alternativo. } \\
\end{array}$ & $\begin{array}{l}\text { La IPS y el médico especialista los delimita y } \\
\text { selecciona la EPS a la que está inscrito el } \\
\text { paciente. Es prácticamente imposible tener } \\
\text { una segunda opinión de un especialista, a no } \\
\text { ser que se page de manera privada. El } \\
\text { sistema en red no contempla e incluye todas } \\
\text { las IPS y médicos y profesionales de la salud } \\
\text { certificados, sino solo con los que ha suscrito } \\
\text { convenios de servicio. Las IPS más pequeñas } \\
\text { y los profesionales independientes terminan } \\
\text { siendo excluidas de las redes de servicios. }\end{array}$ \\
\hline & $\begin{array}{l}\text { Seguimiento a recuperación de la } \\
\text { mano por intervenciones quirúrgicas. } \\
\text { Atención ambulatoria. }\end{array}$ & \begin{tabular}{|l|} 
Bogotá, Colombia. 2020, Metrópolis \\
de siete millones de habitantes. \\
Centro médico de Salud para \\
atención básica. Atención en pleno \\
inicio de pandemia, por lo que no se \\
permitió la entrada del acudiente ni \\
siquiera a la sala de espera.
\end{tabular} & $\begin{array}{l}\text { Consultorio pequeño con elementos y } \\
\text { dispositivos médicos típicos, escritorio, } \\
\text { computador, sistema especializado de } \\
\text { software (historia clínica). Sin camilla y } \\
\text { sin baño, con protocolos de bioseguridad, } \\
\text { pero el consultorio sin adecuada } \\
\text { ventilación. Personal médico: solo el } \\
\text { Ortopedista. La decisión del seguimiento } \\
\text { la basó en revisar la historia clínica y ver } \\
\text { mi mano operada, pero no me indicó } \\
\text { cobertura con más terapias. Me remitió a } \\
\text { cirujano de mano para posterior revisión. } \\
\text { A pesar de falta de terapias y no } \\
\text { recuperación de fuerza y movilidad de la } \\
\end{array}$ & $\begin{array}{l}\text { El sistema de salud vigente no promueve un } \\
\text { proceso de seguimiento riguroso de los } \\
\text { postoperatorios, porque al estar creada bajo } \\
\text { una ley que funciona por empresas de } \\
\text { aseguramiento, se interpreta como gastos } \\
\text { adicionales y no como la verificación de la } \\
\text { completa recuperación de la salud y el } \\
\text { bienestar del paciente. }\end{array}$ \\
\hline
\end{tabular}


ElD Ergonomía, Investigación y Desarrollo, 3(2), 2021, 52-64

\begin{tabular}{|c|c|c|c|c|}
\hline $\begin{array}{l}\text { Propósito del } \\
\text { uso del sistema }\end{array}$ & Acontecimiento analizado & Contexto histórico & $\begin{array}{c}\text { Algunos aspectos del sistema } \\
\text { ergonómico }\end{array}$ & $\begin{array}{l}\text { Aspectos relacionados con el } \\
\text { sistema de salud }\end{array}$ \\
\hline & & & $\begin{array}{l}\text { mano, sin dialogar se limitó a no dar la } \\
\text { orden de no extender la incapacidad } \\
\text { médica. Su atención no sobrepaso los } 10 \\
\text { minutos. }\end{array}$ & \\
\hline \multirow{4}{*}{$\begin{array}{l}\text { Restauración de la salud sin } \\
\text { condición de urgencia }\end{array}$} & $\begin{array}{l}\text { Tapón de cerumen en un oído. } \\
\text { Atención ambulatoria. }\end{array}$ & $\begin{array}{l}\text { México, D.F., México. } 1995 . \\
\text { Metrópolis de 20 millones de } \\
\text { habitantes. Paciente es estudiante } \\
\text { extranjera sin seguro médico. El } \\
\text { valor de la consulta es alto para su } \\
\text { presupuesto. En el artículo cuarto } \\
\text { contemplado en la constitución, dice } \\
\text { que toda persona tiene derecho a la } \\
\text { protección de la salud. }\end{array}$ & $\begin{array}{l}\text { La decisión de ir con un especialista } \\
\text { obedece a la imposibilidad de resolver } \\
\text { por sí misma la situación. El consultorio } \\
\text { cuenta con todo lo necesario para el } \\
\text { procedimiento. La atención y decisiones } \\
\text { se sustentan en la experiencia y } \\
\text { formación del médico especialista. }\end{array}$ & $\begin{array}{l}\text { No hay obligación de aseguramiento, así que } \\
\text { la paciente hace uso del sistema de salud el } \\
\text { sector privado según necesidad (una sola } \\
\text { vez). }\end{array}$ \\
\hline & Amigdalitis. Atención ambulatoria. & $\begin{array}{l}\text { Sinsheim, Alemania. 2004. Ciudad } \\
\text { de 35.00o habitantes. Por ser } \\
\text { atención de especialista, el } \\
\text { desplazamiento se hace a otra } \\
\text { ciudad a una hora de viaje. } \\
\text { Atendidos por el sistema de salud } \\
\text { con cobertura universal. }\end{array}$ & $\begin{array}{l}\text { Consultorio oscuro, con dispositivos } \\
\text { médicos muy viejos, luego de la revisión } \\
\text { de la garganta, muy rápidamente realizó } \\
\text { la nota de remisión para ser operado. }\end{array}$ & \multirow{3}{*}{$\begin{array}{l}\text { Paciente asegurado por el sistema público. } \\
\text { Toda persona en Alemania debe contar con } \\
\text { un seguro médico, bien sea público o } \\
\text { privado. Independientemente de si la } \\
\text { persona está asegurada por medio de su } \\
\text { trabajo o por parte del apoyo social del } \\
\text { gobierno, la persona decide a qué } \\
\text { aseguradora se afilia y tiene a su disposición } \\
\text { prácticamente todas las clínicas y hospitales } \\
\text { disponibles. }\end{array}$} \\
\hline & $\begin{array}{l}\text { Malestar general. Atención } \\
\text { ambulatoria. }\end{array}$ & $\begin{array}{l}\text { Muehlhausen, Alemania. } 2004 . \\
\text { Pueblo de 50oo habitantes. El } \\
\text { consultorio queda a } 5 \text { minutos } \\
\text { caminando de la casa de la paciente. } \\
\text { Atendidos por el sistema de salud } \\
\text { con cobertura universal. }\end{array}$ & $\begin{array}{l}\text { Consultorio médico privado, donde } \\
\text { atienden dos médicos. Equipo normal de } \\
\text { atención médica. La médica hace una } \\
\text { revisión física completa, para luego } \\
\text { indagar sobre asuntos emocionales. Si } \\
\text { bien no encuentra motivos físicos, da } \\
\text { incapacidad laboral de tres días. La } \\
\text { decisión médica vela por una salud } \\
\text { integral. }\end{array}$ & \\
\hline & $\begin{array}{l}\text { Reparación dental. } \\
\text { ambulatoria. }\end{array}$ & $\begin{array}{l}\text { Rossdorf, Alemania. 2011. Pueblo de } \\
\text { 12.ooo habitantes. El consultorio } \\
\text { odontológico queda a } 10 \text { minutos } \\
\text { caminando desde la casa del } \\
\text { paciente. }\end{array}$ & $\begin{array}{l}\text { Consultorio bien iluminado y ventilado, } \\
\text { con todos los dispositivos médicos, } \\
\text { mobiliario e infraestructura para la } \\
\text { atención en salud oral. El personal } \\
\text { médico atiende sin presiones de } \\
\text { sobrecupos y con cumplimiento estricto } \\
\text { de los tiempos de citas durante todo el } \\
\text { tratamiento. Las decisiones del } \\
\text { tratamiento y las acciones a adelantar son } \\
\text { dadas a conocer al paciente tanto de } \\
\text { manera global, como de manera detallada } \\
\text { en cada consulta. }\end{array}$ & \\
\hline
\end{tabular}


EID Ergonomía, Investigación y Desarrollo, 3(2), 2021, 52-64

ISSN 2452-4859

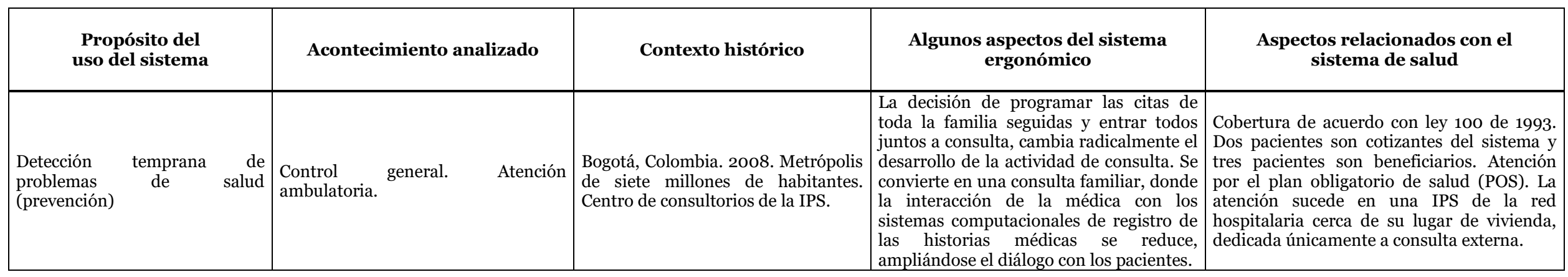

